\title{
Role of macrophage migration inhibitory factor in ovalbumin-induced airway inflammation in rats
}

\author{
M. Kobayashi*, Y. Nasuhara*, A. Kamachi”, Y. Tanino*, T. Betsuyaku*, \\ E. Yamaguchi ${ }^{\oplus}$, J. Nishihira ${ }^{+}$and M. Nishimura*
}

ABSTRACT: Macrophage migration inhibitory factor (MIF) is a pro-inflammatory cytokine that reportedly counteracts the anti-inflammatory effect of endogenous glucocorticoids. There have only been a few reports that demonstrate a potential link between MIF and bronchial asthma. In an attempt to further clarify the precise role of MIF in asthma, the present authors examined the effect of anti-MIF antibody (Ab) on airway inflammation and airway hyperresponsiveness in an ovalbumin-immunised rat asthma model.

Actively immunised Brown Norway rats received ovalbumin inhalation with or without treatment of anti-MIF Ab. The levels of MIF in bronchoalveolar lavage fluid were significantly elevated after the ovalbumin challenge.

An immunohistochemical study revealed positive immunostaining for MIF in bronchial epithelium, even in nonsensitised rats, and the MIF staining in bronchial epithelium was enhanced after the ovalbumin challenge. Anti-MIF Ab significantly decreased the number of total cells, neutrophils and eosinophils in the bronchoalveolar lavage fluid of the ovalbumin-challenged rats, and also attenuated the ovalbumin-induced airway hyperresponsiveness to ovalbumin and methacholine. However, anti-MIF Ab did not affect the level of serum ovalbumin-specific IgE, suggesting that anti-MIF Ab did not suppress immunisation itself.

The results indicate that macrophage migration inhibitory factor plays a crucial role in airway inflammation and airway hyperresponsiveness in asthma.

KEYWORDS: Airway hyperresponsiveness, airway inflammation, asthma, eosinophil, macrophage migration inhibitory factor, ovalbumin

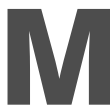
acrophage migration inhibitory factor (MIF) was first described as one of the earliest cytokines to be derived from activated T-cells and to prevent the random migration of macrophages [1, 2]. Cloning of human MIF cDNA has led to extensive studies using purified recombinant MIF [3]; this protein has been postulated to function as a proinflammatory cytokine [4, 5]. DONNELLY et al. [6] reported that the levels of MIF in bronchoalveolar lavage fluid (BALF) were increased in patients with acute respiratory distress syndrome. The present authors subsequently demonstrated that anti-MIF antibody (Ab) attenuated both lipopolysaccharide-induced neutrophil accumulation in rat lungs [7] and bleomycin-induced acute lung inflammation and mortality in mice [8]. These data support the idea that MIF is a proinflammatory cytokine involved in lung injury.

MIF is now known to be constitutively expressed in a variety of cells, including macrophages,
T-cells and bronchial epithelial cells in the lungs $[4,7,9]$. It has the unique feature of overriding the anti-inflammatory and immunosuppressive effects of glucocorticoids [5, 10]. MIF also plays an important regulatory role in the activation of $\mathrm{T}$-cells induced by mitogenic or antigenic stimuli [11]. The strong induction of MIF mRNA and protein has been observed from T-helper cell (Th) type 2 but not Th1 clones [11]. Accordingly, MIF is considered to be a pleiotropic peptide, functioning as a cytokine and/or hormone.

Only a few reports have examined the potential role of MIF in asthma [12-14]. Rossi et al. [12] first reported that MIF levels were increased in BALF from asthmatic patients and that circulating eosinophils could produce MIF upon stimulation in vitro. However, one subsequent animal study could not support this argument of the role of MIF in asthma because anti-MIF serum did not affect allergic airway inflammation in mice [14]. The aim of the present study is to further clarify

\section{AFFILIATIONS}

*First Dept of Medicine and ${ }^{+}$Central Research Institute, Hokkaido University School of Medicine, Sapporo, and

\#Dept of Respiratory Medicine, 0ji Municipal General Hospital,

Tomakomai, and

"Division of Respiratory Medical and Allergy Dept of Internal Medicine, Aichi Medical University School of Medicine, Aichi, Japan.

\section{CORRESPONDENCE}

Y. Nasuhara

First Dept of Medicine Hokkaido University School of Medicine

North 15 West 7

Kita-ku

Sapporo 060-8638

Japan

Fax: 81117067899

E-mail:

nasuhara@med.hokudai.ac.jp

Received:

September 142004

Accepted after revision:

January 052006 
the role of MIF in asthma using rats. The study will demonstrate that anti-MIF $\mathrm{Ab}$ inhibits ovalbumin (OA)induced airway inflammation as well as airway hyperresponsiveness in Brown Norway rats, which have been used as a model of atopic asthma [15-17].

\section{MATERIALS AND METHODS Animals and immunisation}

The research adhered to the Declaration of Helsinki and was approved by the Ethical Committee on Animal Research (Hokkaido University, Sapporo, Japan). Specific pathogen-free 6-week-old male Brown Norway rats (weight range, 160-200 g) were purchased from Japan Charles River Co. (Yokohama, Japan). They were actively immunised to OA by subcutaneous injection with $1 \mathrm{mg}$ OA containing $200 \mathrm{mg}$ aluminum hydroxide. An adjuvant consisting of $1 \times 10^{9}$ heat-killed Bordetella pertussis organisms was intraperitoneally injected at the same time.

\section{Preparation of rabbit polyclonal Ab against MIF}

Polyclonal anti-rat MIF serum was generated by immunising New Zealand White rabbits with purified recombinant rat MIF. Rat MIF was expressed in Escherichia coli and purified to homogeneity, as described in a previous publication of the authors' [18]. In brief, the rabbits were inoculated intradermally with $100 \mathrm{mg}$ of MIF emulsified in complete Freunds adjuvant (Wako Pure Chemical Industries, Osaka, Japan) at weeks 1 and 2, and with $50 \mathrm{mg}$ of MIF diluted in incomplete Freunds' adjuvant (Wako Pure Chemical Industries) at week 4. The immunoglobulin (Ig)G fraction was prepared using Protein A Sepharose (GE Healthcare Bio-Sciences, Piscataway, NJ, USA) according to the manufacturer's protocol.

\section{Experimental protocol}

The rats were divided into three groups: Naive group, OA group, and OA+anti-MIF Ab group. The Naive group did not receive immunisation and did not have any treatments. The $\mathrm{OA}$ and $\mathrm{OA}+$ anti-MIF Ab groups were actively immunised on day 0 and intraperitoneally injected with $2 \mathrm{mg}$ of the nonimmunised rabbit IgG or the anti-MIF polyclonal Ab every 2 days from day 0 to day 16 . In the preliminary study, the present authors had confirmed that non-immunised rabbit IgG caused no changes in inflammatory cells of the OA-immunised lungs. Neither total cell nor eosinophil counts in BALF were significantly different between the $\mathrm{OA}$ immunised+untreated group and the OA immunised+non-immunised IgG group $\left(8.99 \pm 1.70 \times 10^{6} \quad\right.$ versus $7.05 \pm 0.89 \times 10^{6} \quad \mathrm{n}=3$, and $5.79 \pm 0.76 \times 10^{6}$ versus $4.67 \pm 0.80 \times 10^{6} \mathrm{n}=3,3$, respectively; unpublished data). The OA immunised+non-immunised IgG group were thus used as control in this experiment. The authors felt that administration of non-immunised rabbit IgG would be desirable to more specifically examine the effect of anti-MIF $\mathrm{Ab}$. On day 14 , the rats inhaled $2 \%$ weight/volume OA for $15 \mathrm{~min}$ in an exposure chamber. Three days after OA inhalation, broncoalveolar lavage was performed, blood samples and lung tissues were taken, and the airway response to OA or methacholine (Mch) was measured.

\section{Bronchoalveolar lavage and cell counting}

The lungs were washed three times with $15 \mathrm{~mL}$ of sterile saline. After the lavage, the lungs were fixed with an intrabronchial infusion of $10 \%$ neutral formalin at a constant pressure of $25 \mathrm{cmH}_{2} \mathrm{O}$ for 48 -h period. The lavage fluid was centrifuged and the cells were counted and processed for differential cell analysis. The supernatant was used for the measurement of MIF, eotaxin, or interleukin (IL)-13 concentrations.

\section{Measurement of bronchial responsiveness to methacholine and ovalbumin}

Three days after OA challenge, another set of three groups were anaesthetised with an intraperitoneal injection of pentobarbital sodium $\left(50 \mathrm{mg} \cdot \mathrm{kg}^{-1}\right)$. Intratrachial intubation was then performed with a metallic tube. The rats were mechanically ventilated (Rodent Ventilator Model 683; Harvard Apparatus, Holliston, MA, USA). A pressure transducer (TP-602T; Nihon Kohden Co., Tokyo, Japan) was connected to a side port of the metallic tube, and airway opening pressure $(P a)$ was continuously measured. An aerosol of Mch or OA was administered through a reservoir box connected to the ventilator system. After measurement of baseline $P$ ao, an aerosol of saline followed by Mch or OA was administered.

\section{Immunohistochemical study}

Immunohistochemistry was performed according to the manufacturer's protocol on paraffin embedded tissue using a Catalized Signal Amplification kit (DAKO Japan, Kyoto, Japan). The primary Ab was anti-MIF diluted at 1:200 with PBS. The tissue sections were counterstained with methyl green and mounted. The anti-MIF Ab used for immunohistochemical study was the same as the $\mathrm{Ab}$ administered for treatment of rats.

\section{Measurement of MIF levels by ELISA}

The levels of MIF in the BALF were quantitated using the ELISA method, as described in a previous publication [19]. The anti-rat MIF $\mathrm{Ab}$ administered for treatment of rats was used in ELISA. Briefly, the anti-rat MIF Ab was added to each well of a 96-well microtitre plate. Wells were incubated with biotinconjugated anti-MIF $\mathrm{Ab}$ for $1 \mathrm{~h}$ at room temperature. Avidinconjugated horseradish peroxidase was added after washing. Substrate solution was then added to each well. The reaction was terminated with $2 \mathrm{M}$ sulphuric acid. The absorbance was measured at $492 \mathrm{~nm}$ on an automated ELISA plate reader. The detection limit of this system was $1.5 \mathrm{ng} \cdot \mathrm{mL}^{-1}$.

\section{OA-specific IgE Ab assay}

The levels of OA-specific IgE in serum were quantitated using an ELISA method, as previously described [20]. Briefly, the 96well microtitre plates were coated with anti-rat $\operatorname{IgE}$ monoclonal $\mathrm{Ab}$ (Zymed, South San Francisco, CA, USA) at $4^{\circ} \mathrm{C}$ for $24 \mathrm{~h}$. The plate was washed and incubated with standard serum or sample serum for $1 \mathrm{~h}$ at room temperature. After washing, horseradish peroxidase-streptavidin was plated into each well. After final washing, o-phenylenediamine solution containing $0.035 \%$ hydrogen peroxide was added to each well. The enzyme reaction was stopped by the addition of $2 \mathrm{M}$ sulphuric acid and the absorbance was measured at $490 \mathrm{~nm}$ on a plate reader. The absorbance of standard serum diluted 1:100 was arbitrarily defined as $\mathrm{U} \cdot \mathrm{mL}^{-1}$. 
Measurement of eotaxin and IL-13 concentrations by ELISA Due to the high degree of similarity maintained in chemokines across species, a mouse ELISA kit (R\&D Systems Inc., Minneapolis, MN, USA) containing a polyclonal $\mathrm{Ab}$ that recognizes mouse eotaxin was used to detect the rat cognate. Eotaxin levels in BALF were determined using this kit according to the manufacturer's instructions. IL-13 levels in BALF were determined using a rat-specific solid phase sandwich ELISA kit (Biosource International, Camarillo, CA, USA). The minimum detectable concentration of eotaxin was $3 \mathrm{pg} \cdot \mathrm{mL}^{-1}$; IL-13 was $1.5 \mathrm{pg} \cdot \mathrm{mL}^{-1}$.

\section{Statistical analysis}

Data are expressed as mean \pm SEM. Statistical analyses were performed on the data using single-factor ANOVA on the three groups and with a Student's unpaired t-test for comparisons of two groups. A p-value of $<0.05$ was assumed to be significant.

\section{RESULTS}

\section{Expression of MIF in OA-induced airway inflammation}

To investigate whether the expression of MIF in airways was enhanced in this model, the levels of MIF in BALF were measured 3 days after the OA challenge. They were significantly elevated in the OA group compared with those in the Naive group $\left(14.7 \pm 1.4\right.$ versus $1.3 \pm 1.1 \mathrm{ng} \cdot \mathrm{mL}^{-1}$, respectively, $\mathrm{p}<0.05$; fig. 1).

\section{Immunohistochemical localisation of MIF in lungs}

Histological examination using the lung tissue confirmed that OA inhalation induced widespread peribronchiolar inflammation in OA-sensitised rats, which is characteristic of asthma. Positive immunostaining for MIF was observed within the bronchial epithelium, even in the Naive group (fig. 2a). There was a significant increase in immunostaining of the bronchial epithelial cells, epithelial submucosa and inflammatory cells in the alveoli of the OA group 3 days after the OA challenge (fig. 2b).

\section{Effect of anti-MIF Ab on airway inflammation}

Total and differential cell counts 3 days after the OA challenge are shown in figure 3 . In the OA group, the numbers of total

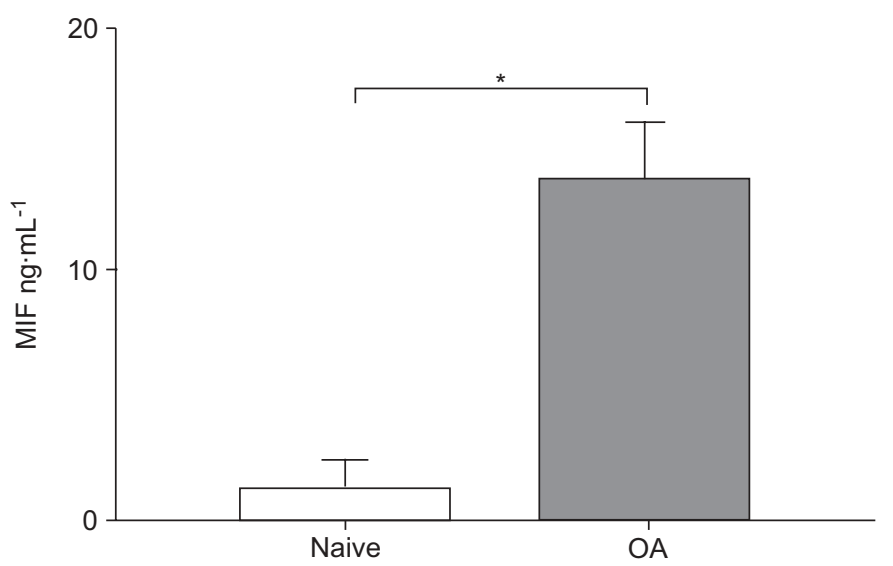

FIGURE 1. Levels of macrophage migration inhibitory factor (MIF) in bronchoalveolar lavage fluid (BALF). MIF in BALF significantly increased 3 days after the ovalbumin $(O A)$ challenge in the OA group $(n=6)$ compared with the Naive group $(n=3)$. *: $p<0.05$. cells, macrophages, eosinophils and neutrophils were significantly elevated compared with those of the Naive group. Treatment with anti-MIF $\mathrm{Ab}$ significantly decreased the numbers of total cells, eosinophils and neutrophils compared with those of the OA group (total cells: $15.0 \pm 3.5 \times 10^{6}$ in the OA group versus $10.5 \pm 2.4 \times 10^{6}$ in the OA+anti-MIF Ab group, $\mathrm{p}<0.01$; eosinophils: $10.5 \pm 2.7 \times 10^{6}$ in the OA group versus $6.2 \pm 2.7 \times 10^{6}$ in the OA+anti-MIF Ab group, $\mathrm{p}<0.01$

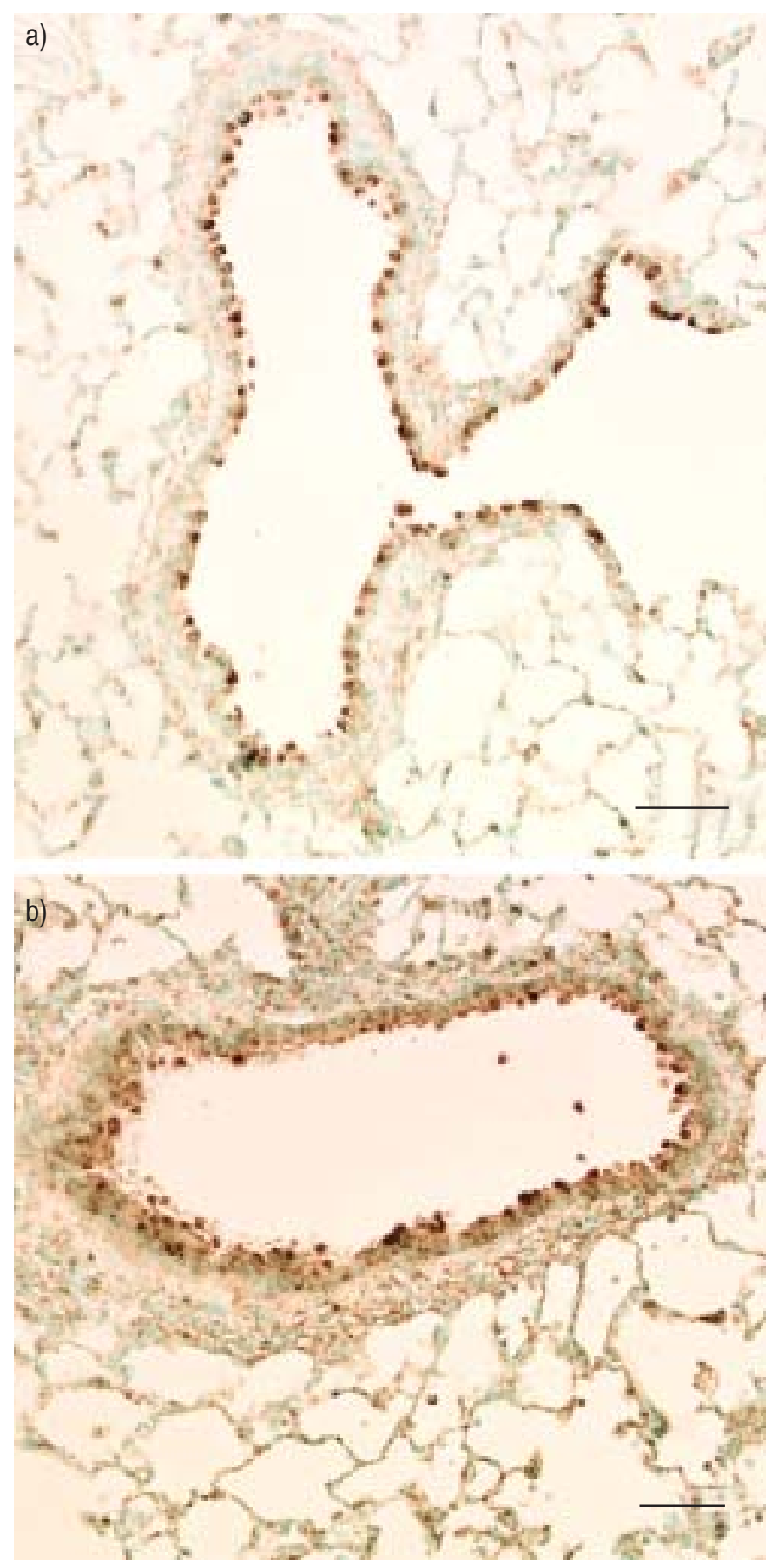

FIGURE 2. Immunohistochemistry of macrophage migration inhibitory factor (MIF) in the lung. a) MIF was weakly detected in airway epithelium in the Naive group. b) MIF was prominent in airway epithelium in the ovalbumin (OA) group 3 days after the OA challenge. Scale bars $=100 \mu \mathrm{m}$. 
neutrophils: $1.4 \pm 1.2 \times 10^{6}$ in the OA group versus $0.16 \pm 0.27$ $\times 10^{6}$ in the OA+anti-MIF Ab group, $\mathrm{p}<0.01$ ) and thus significantly attenuated airway inflammation.

\section{Effect of anti-MIF Ab on antigen-specific airway contraction and nonspecific airway hyperresponsiveness}

To investigate whether anti-MIF Ab suppressed airway hyperresponsiveness, OA-specific and Mch-induced airway contractions were measured. After measurement of the baseline pressure, an aerosol of OA was administered. The airway pressure was significantly increased in the OA group (fig. 4a) but not in the OA+anti-MIF Ab group (fig. 4b). Similarly, after measurement of the baseline pressure, an aerosol of Mch was administered for $1 \mathrm{~min}$ in progressively doubled concentrations from $0.0625 \mathrm{mg} \cdot \mathrm{mL}^{-1}$. In the OA group, the airway pressure was significantly increased. In contrast, the OAtantiMIF $\mathrm{Ab}$ group did not respond to Mch (up to $16.0 \mathrm{mg} \cdot \mathrm{ml}^{-1}$ ). The Naive group did not respond to either $5 \%$ OA or Mch (up to $16.0 \mathrm{mg} \cdot \mathrm{ml}^{-1}$; data not shown).

\section{Effect of anti-MIF Ab on the development of humoral immune responses}

Elevated levels of $\mathrm{IgE}$ are known to be important in the development of an allergen-induced airway response [21]. The results described above may be a consequence of suppression
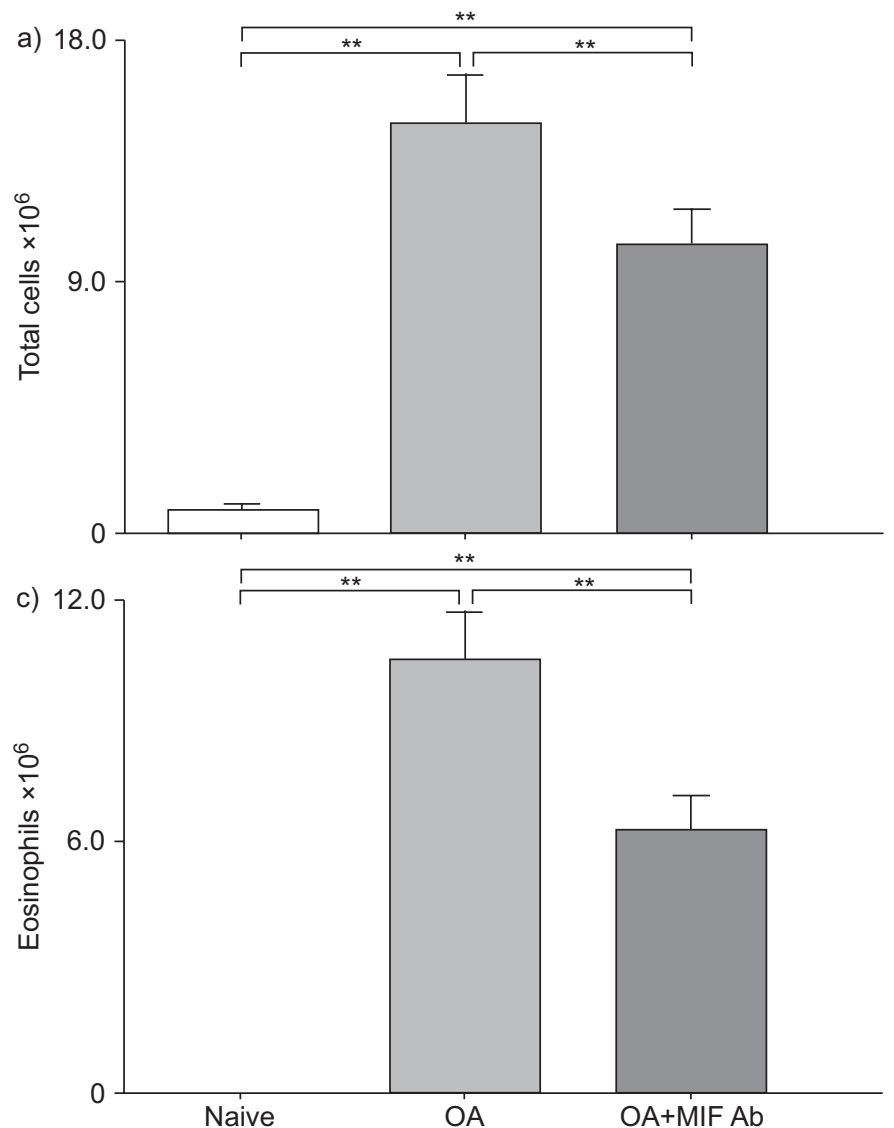

of OA immunisation by treatment of anti-MIF $\mathrm{Ab}$; the authors therefore examined the possibility that anti-MIF $\mathrm{Ab}$ might have influenced OA-specific IgE levels in serum. As shown in figure 5, as expected [16], the levels of OA-specific IgE in serum were significantly elevated in the OA group compared with those in the Naive group $\left(124.0 \pm 41.3 \mathrm{U} \cdot \mathrm{mL}^{-1}\right.$ in the OA group versus $18.6 \pm 5.7 \mathrm{U} \cdot \mathrm{mL}^{-1}$ in the Naive group, $\left.\mathrm{p}<0.05\right)$. Treatment with anti-MIF Ab similarly caused the elevation of OA-specific IgE in serum $\left(153.3 \pm 39.6 \mathrm{U} \cdot \mathrm{mL}^{-1}\right)$.

\section{Effect of a single administration of anti-MIF Ab before airway challenge}

The authors next considered whether the single administration of anti-MIF $\mathrm{Ab}$ before $\mathrm{OA}$ challenge might explain the results described above. A 2-mg aliquot of anti-MIF Ab or nonimmunised rabbit IgG was injected only once $2 \mathrm{~h}$ before OA challenge and bronchoalveolar lavage was performed 3 days after OA challenge. As shown in figure 6, a single administration of anti-MIF $\mathrm{Ab}$ did not change either the number of total cells or the differential cell counts in BALF.

\section{Effect of anti-MIF Ab on eotaxin levels in BALF}

To investigate the mechanism by which anti-MIF Ab attenuated eosinophil accumulation in the lungs, the levels of

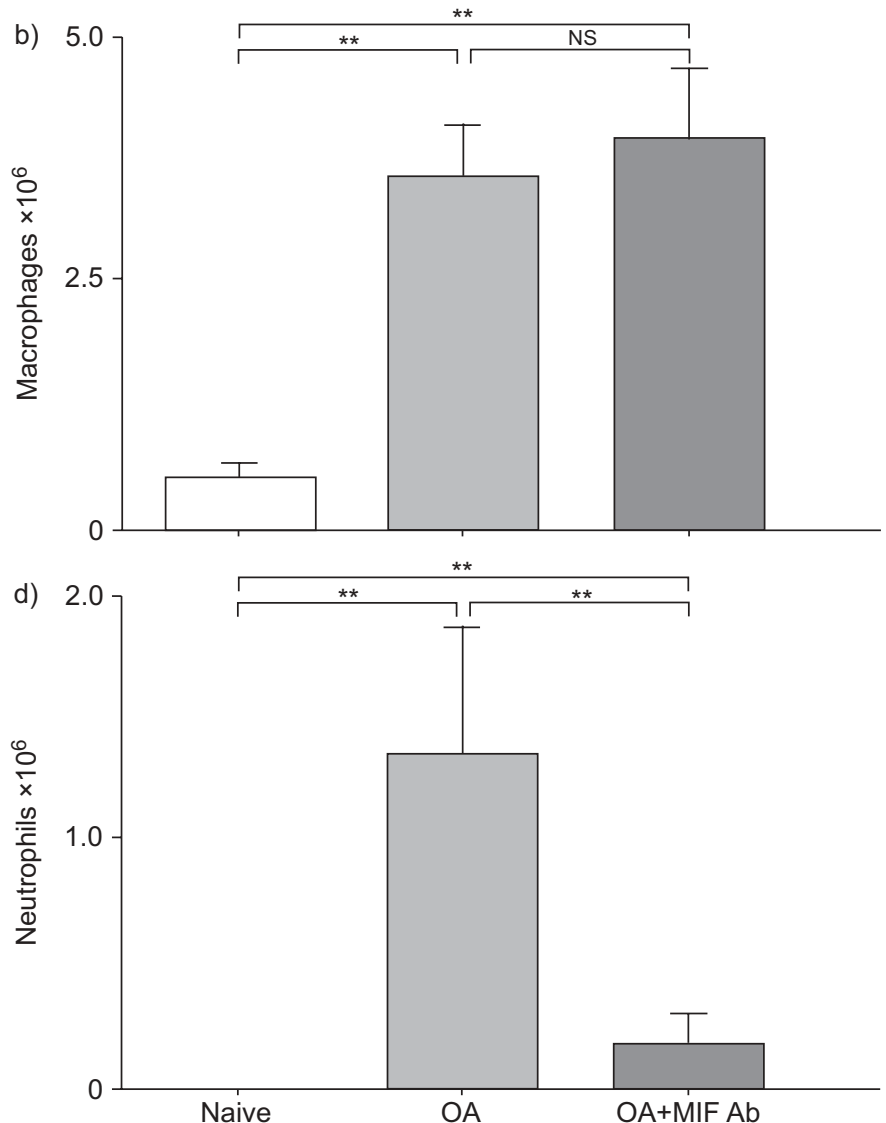

FIGURE 3. Total and differential cell counts in bronchoalveolar lavage fluid. Bronchoalveolar lavage was performed 3 days after ovalbumin (OA) challenge. The numbers of a) total cells, b) macrophages, c) eosinophils and d) neutrophils were significantly elevated in the OA group in comparison with the Naive group. Treatment with antimigration inhibitory factor antibody (OA+MIF Ab) significantly decreased the numbers of total cells (a), eosinophils (c) and neutrophils (d) $(n=6)$. **: $p<0.01 ;$ NS: nonsignificant. 

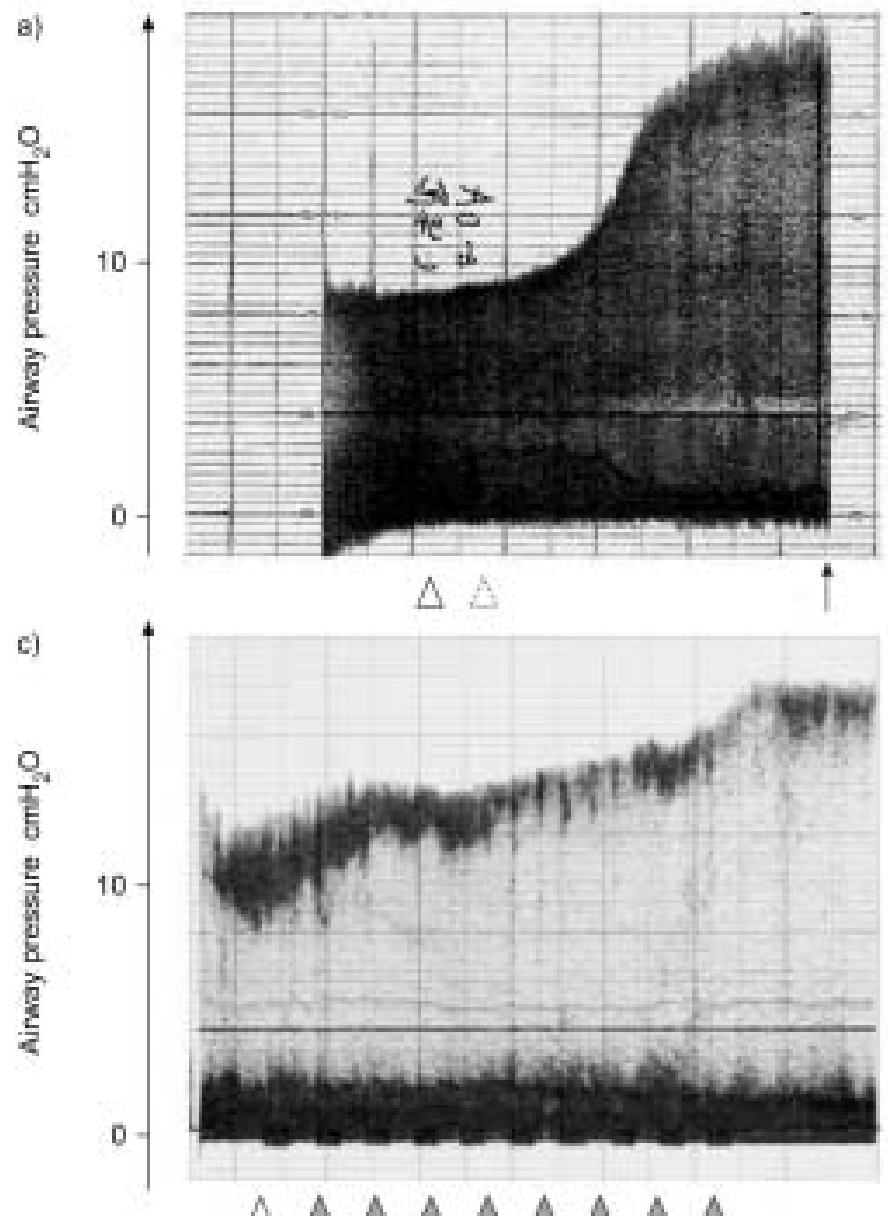

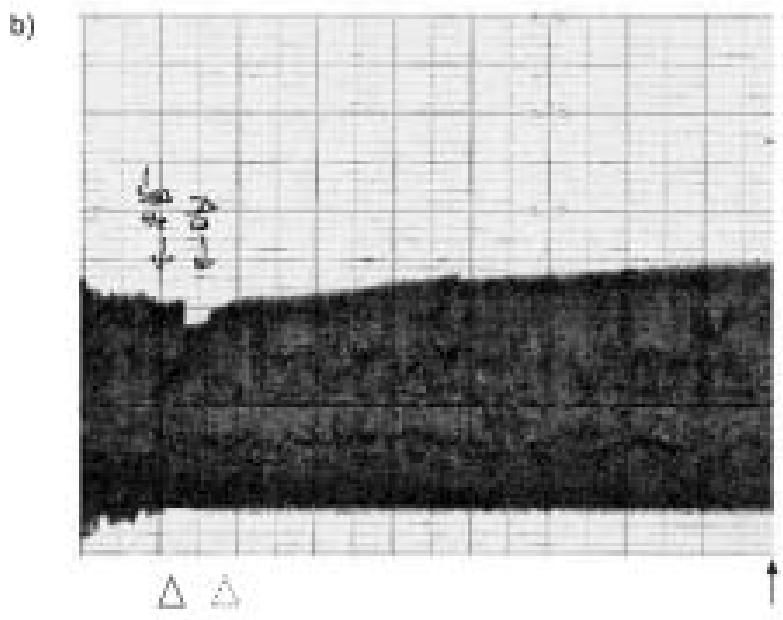

d)

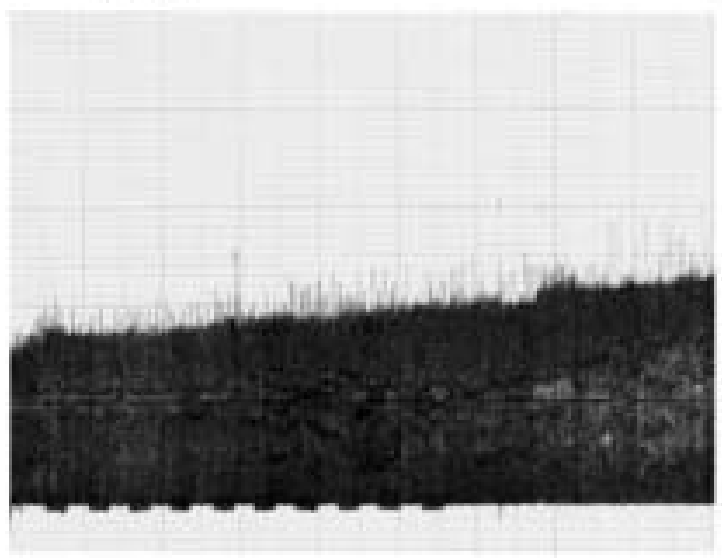

$\triangle \Delta \Delta \Delta \Delta \Delta \Delta \Delta \Delta$

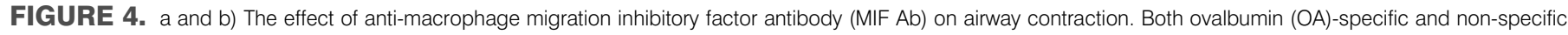

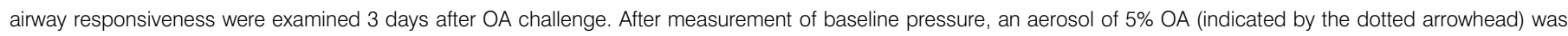

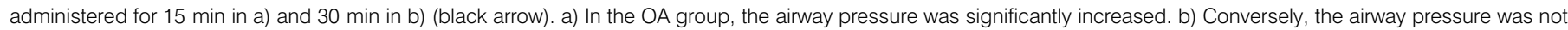

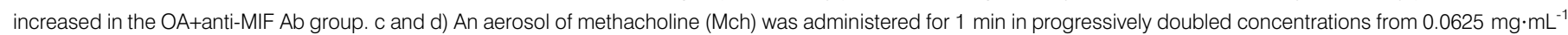

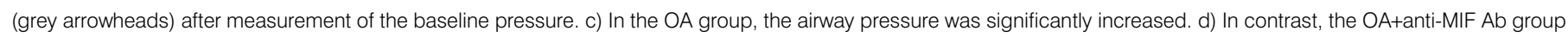
did not respond to Mch even at the maximum dose, $16 \mathrm{mg} \cdot \mathrm{mL}^{-1}$. Results are representative of three independent experiments. Open arrowhead: saline inhalation.

eotaxin, a potent chemokine of eosinophils, in BALF were measured. In the study series up to $24 \mathrm{~h}$ after OA challenge, the levels of eotaxin in BALF began to increase at $4 \mathrm{~h}$ and reached peak levels at $8 \mathrm{~h}$ in the OA group; however, no appreciable increase was seen in the levels of the Naive group (data not shown). No significant difference was seen in eotaxin levels at $8 \mathrm{~h}$ after the $\mathrm{OA}$ challenge between the $\mathrm{OA}$ group and the OA+anti-MIF Ab group $\left(8.24 \pm 1.5 \mathrm{pg} \cdot \mathrm{mL}^{-1}\right.$ in the Naive group, $127.3 \pm 38.0 \mathrm{pg} \cdot \mathrm{mL}^{-1}$ in the OA group, and $160.0 \pm 23.3 \mathrm{pg} \cdot \mathrm{mL}^{-1}$ in the OA+anti-MIF $\mathrm{Ab}$ group; fig. 7a).

\section{Effect of anti-MIF Ab on IL-13 levels in BALF}

The levels of IL-13 in BALF were also measured. The levels were significantly elevated at $8 \mathrm{~h}$ after OA challenge in the OA group compared with the Naive group. However, no significant difference was seen in IL-13 levels between the OA group and the OA+anti-MIF $\mathrm{Ab}$ group $\left(31.2 \pm 5.2 \mathrm{pg} \cdot \mathrm{mL}^{-1}\right.$ in the Naive group, $63.0 \pm 16.9 \mathrm{pg} \cdot \mathrm{mL}^{-1}$ in the OA group, and $72.4 \pm 8.1 \mathrm{pg} \cdot \mathrm{mL}^{-1}$ in the OA+anti-MIF Ab group; fig. $7 \mathrm{~b}$ ).

\section{DISCUSSION}

This study first demonstrated that OA-sensitised rats had increased levels of MIF in BALF and enhanced expression of MIF in airway epithelium after OA challenge. These results are consistent with the previous observation in a human study in which BALF from patients with asthma contained significantly elevated levels of MIF as compared to normal volunteers [12]. In addition, it has been clearly demonstrated that treatment with anti-MIF Ab significantly suppressed airway inflammation and airway hyperresponsiveness, both of which are characteristic features in this rat model of atopic asthma. These results indicate that MIF plays a potent role in the pathogenesis of allergen-induced airway inflammation and that anti-MIF Ab may have a therapeutic potential for bronchial asthma.

The present study does not agree with a previous study in which anti-MIF serum did not affect the allergic inflammation of the airway in mice [14]. In that study, mice were exposed to OA once daily for 7 days following active immunisation by $\mathrm{OA}$ 


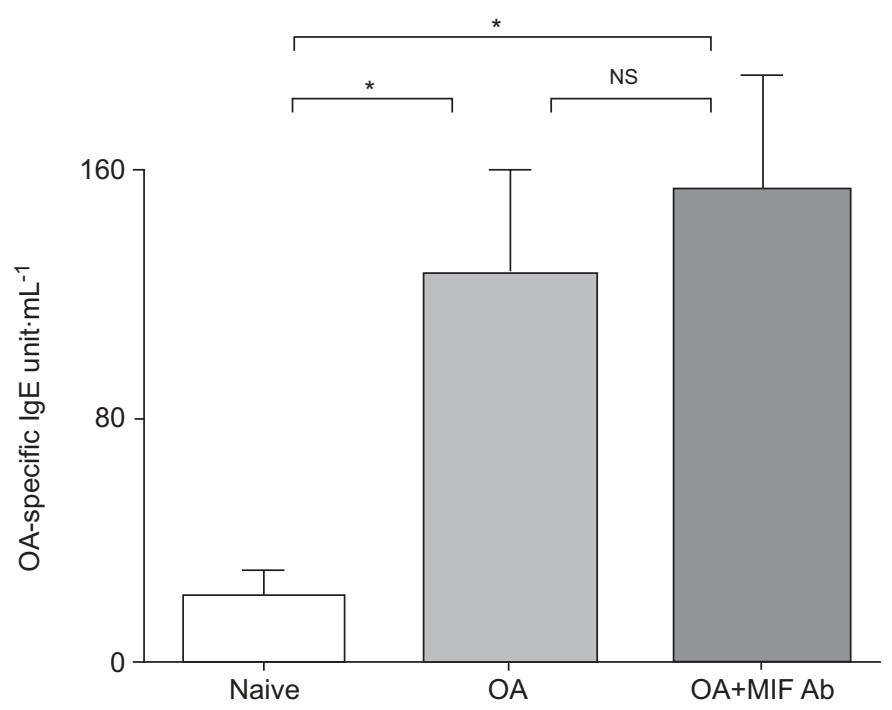

FIGURE 5. Effect of anti-macrophage migration inhibitory factor antibody (MIF $\mathrm{Ab}$ ) on ovalbumin (OA)-specific immunoglobulin (Ig)E levels in serum. Serum was removed from the inferior vena cava 3 days after the $O A$ challenge $(n=6)$. The levels of OA-specific IgE in serum were significantly elevated in the OA group after OA challenge compared with those in the Naive group. There was no significant difference between the OA group and the OA+anti-MIF Ab group. *: $p<0.05$; NS: nonsignificant.

injection and were treated with anti-MIF serum every 3 days from the day before the first allergen challenge to the end of the experiment. Such treatment did not significantly reduce the number of eosinophils either in lung tissues or BALF. The discrepancy between the two studies with regard to the effect of anti-MIF on eosinophil recruitment into the airway requires some explanation. First, the eosinophilic inflammation induced in the other study was milder than that observed in the present study; the percentage of eosinophils in BALF was nearly $30 \%$ in the other study and $64.9 \pm 3.7 \%$ in the present study. The small number of eosinophils in the other study might have obscured the inhibitory effect of anti-MIF Ab. Secondly, researchers in the other study used anti-MIF serum rather than anti-MIF $\mathrm{Ab}$, and the total dose of anti-MIF serum given might not have been sufficient. Indeed, although the previous study also investigated the effect of anti-MIF serum on lipopolysaccharide-induced neutrophilic airway inflammation, the researchers could not demonstrate the effect of the antiMIF serum either. In contrast, the present authors previously demonstrated that anti-MIF Ab significantly inhibited lipopolysaccharide-induced neutrophil accumulation in rat lungs [7]. Taken together, the anti-MIF serum used in the other study may not have had enough potency or may not have been given in a sufficient amount to exert a discernable effect. A less likely possibility for the discrepancy between the two studies is that the role of MIF in animal models of asthma may differ among species.

MIF is known to be constitutively expressed in bronchial epithelium [7, 9]. In the present study, the immunohistochemical experiment clearly demonstrated that expression of MIF was enhanced in airway epithelium after OA challenge in OA-sensitised rats. This is the first study to demonstrate that bronchial epithelium is a potent source of MIF in an asthma model. Previously, Rossi et al. [12] suggested that eosinophils might be a potential source of MIF in human asthma because even circulating eosinophils from normal volunteers were shown to produce MIF with phorbol myristate acetate stimulation. Indeed, in the present study, the majority of inflammatory cells in BALF were eosinophils. Accordingly, bronchial epithelium as well as eosinophils may jointly contribute to the increased levels of MIF in BALF in the present rat asthma model.

Because $60-70 \%$ of total cells in BALF in OA-sensitised rats were eosinophils, the attenuation of the number of total cells by treatment with anti-MIF $\mathrm{Ab}$ is mostly attributed to the attenuation of the number of eosinophils. It has been reported that the eotaxin levels are highly elevated in BALF from patients with asthma [22] and that eotaxin is associated with airway hyperresponsiveness [23]. Eotaxin may therefore play an important role in the pathogenesis of bronchial asthma. As a result, the present authors wondered whether the effect of the anti-MIF Ab on airway inflammation might be at least in part explained by its effect on eotaxin. It was found that the level of eotaxin in BALF was certainly elevated after OA challenge compared with that in naive rats. However, no significant difference was observed in the levels of eotaxin in BALF between the OA group and the OA+anti-MIF Ab group. In animal models, IL-13 has been shown to induce airway hyperresponsiveness and airway eosinophilia [24, 25]. It is also possible that IL-13-dependent airway hyperresponsiveness occurs via mechanisms that are independent of airway eosinophilia [26]. In the present study, the levels of IL-13 in BALF were elevated after OA challenge; however, there was no significant difference between the OA group and the $\mathrm{OA}+$ anti-MIF $\mathrm{Ab}$ group. The authors also measured the expression of IL-5 mRNA and macrophage inflammatory protein (MIP)- $1 \alpha$ mRNA using tissue homogenates after OA challenge. These chemokines are known to have a role in the recruitment of eosinophils to airways in asthma. However, the level of mRNA for MIP- $1 \alpha$ did not increase after antigen challenge and that of IL-5 was under the detection limits, even after antigen challenge in this model (data not shown). A previous study reported that MIF significantly delayed spontaneous neutrophil apoptosis in vitro, as well as eosinophil apoptosis to some extent [27]. Thus, the anti-MIF Ab might reduce the number of eosinophils and neutrophils in BALF by enhancing apoptosis of those cells.

The anti-MIF $\mathrm{Ab}$ dramatically reduced the number of neutrophils in BALF in the present study. Neutrophils are known to be increased in the airways of patients with status asthmaticus [28], during exacerbations of asthma [29] and in sputum from subjects with severe asthma [30]. However, the role of neutrophils in asthma is not fully understood. The attenuation of the number of neutrophils may be partially attributed to the anti-inflammatory effect of anti-MIF Ab in the present model. The authors have previously reported that antiMIF Ab inhibits lipopolysaccharide-induced neutrophil accumulation in rat lungs via its suppressive effect on MIP-2, a powerful neutrophil chemokine [7]. Therefore, the suppression of MIP-2 might cause attenuation of the number of neutrophils in the rat asthma model. 

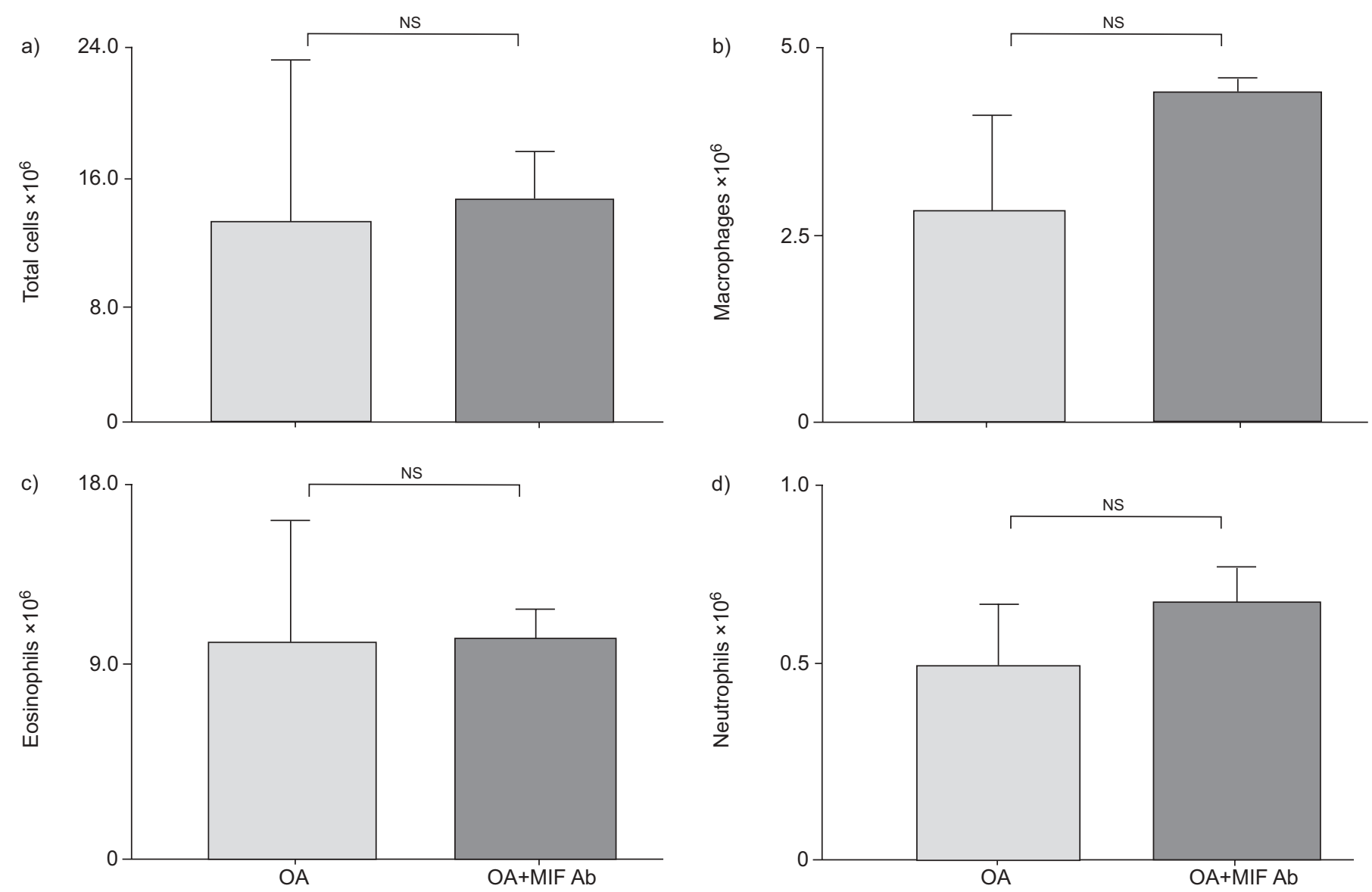

FIGURE 6. Effect of single administration of anti-macrophage migration inhibitory factory antibody (MIF Ab) on a) total cells, b) macrophages, c) eosinophils and d) neutrophils in bronchoalveolar lavage fluid (BALF). A 2-mg aliquot of anti-MIF Ab or rabbit IgG was injected once, $2 \mathrm{~h}$ before ovalbumin (OA) challenge and bronchoalveolar lavage was performed 3 days after OA challenge. A single administration of anti-MIF Ab did not reduce the number of total and differential cell counts in BALF ( $\mathrm{n}=3$ ).

In the present study, the anti-MIF $\mathrm{Ab}$ did not affect antigenspecific IgE in serum, which led to investigation of whether a single dose of anti-MIF $\mathrm{Ab}$ could exert its effect before OA inhalation. A single administration of anti-MIF $\mathrm{Ab}$ did not reduce the number of total cells and differential cell counts in $\mathrm{BALF}$, suggesting that the serial injection of the anti-MIF Ab from OA sensitisation to 2 days after OA inhalation are necessary for its suppressive effect to be exerted. The total amount of anti-MIF $\mathrm{Ab}$ might be important for exertion of its effect. It was therefore concluded that anti-MIF Ab suppressed OA-induced airway inflammation by an independent mechanism of OA-sensitisation.

Glucocorticoids are currently the most effective anti-inflammatory agent in the treatment of asthma [31]. However, it is widely recognised that a small proportion of patients, who are often named as steroid-resistant asthmatics, fail to respond to glucocorticoids. MIF might play a role in the blunt response to endogenous or exogenous steroids $[5,10]$. This consideration leads to the speculation that anti-MIF therapy may not only have direct anti-inflammatory effects, but also act by recovering the function of endogenous and/or exogenous glucocorticoids.

Finally, some comments should be made on the weakness of the experimental protocol in this study. First, quantitative assessment of airway hyperresponsiveness was not performed, particularly for naive rats and OA+anti-MIF $\mathrm{Ab}$ rats; this meant it was unclear how much anti-MIF $\mathrm{Ab}$ attenuated airway hyperresponsiveness in the OA-immunised lungs. Such assessment was not performed because the authors' specific interest lay in assuring that enhanced airway hyperresponsiveness by OA immunisation and inhalation was actually attenuated by anti-MIF Ab. Secondly, airway pressure was used to assess airway hyperresponsiveness, which is influenced by changes in both airway resistance and lung compliance. As the increased airway pressure was confirmed to return to baseline in a short time, the change of compliance, which is likely to be caused by lung parenchymal injury, could be negligible in the present study (data not shown).

In summary, the present manuscript has demonstrated that macrophage migration inhibitory factor is involved in the asthmatic response in the ovalbumin-sensitised rat asthma model. It has also been shown that bronchial epithelium is a potent source of macrophage migration inhibitory factor in this asthma model. The anti-macrophage migration inhibitory factor antibody also significantly attenuated ovalbumininduced airway inflammation and airway hyperresponsiveness. Although these data support the concepts that macrophage migration inhibitory factor plays an important 

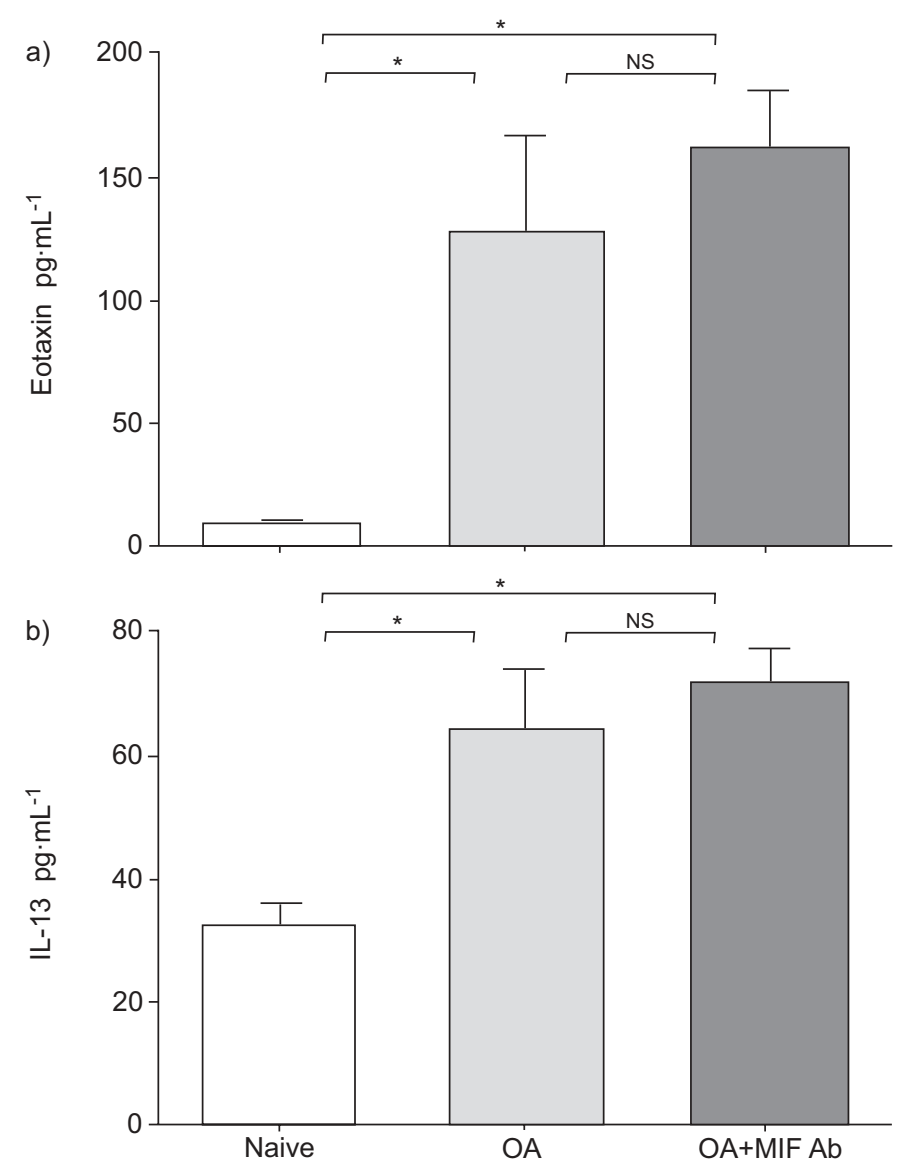

FIGURE 7. Effects of anti-macrophage migration inhibitory factory antibody (MIF Ab) on a) eotaxin and b) interleukin (IL)-13 levels in bronchoalveolar lavage fluid (BALF). The levels of eotaxin and IL-13 in BALF were significantly elevated in the ovalbumin $(\mathrm{OA})$ group compared with the Naive group $8 \mathrm{~h}$ after the $\mathrm{OA}$ challenge. However, there were no significant differences in both chemokines between the OA group and the OA+anti-MIF Ab group ( $n=3$ for each).

role in asthma and anti-macrophage migration inhibitory factor antibody may have a therapeutic potential for asthma, further investigations are necessary to fully understand the mechanism of the effect of anti-macrophage migration inhibitory factor antibody on asthma pathology and to examine the therapeutic potential of the anti-macrophage migration inhibitory factor antibody in human asthma.

\section{REFERENCES}

1 Bloom BR, Bennett B. Mechanism of a reaction in vitro associated with delayed-type hypersensitivity. Science 1996; 153: 80-82.

2 David JR. Delayed hypersensitivity in vitro: its mediation by cell-free substances formed by lymphoid cellantigen interaction. Proc Natl Acad Sci USA 1966; 56: 72-77.

3 Weiser WY, Temple PA, Witek-Giannotti JS, Remold HG, Clark SC, David JR. Molecular cloning of a cDNA encoding a human macrophage migration inhibitory factor. Proc Natl Acad Sci USA 1989; 86: 7522-7526.
4 Baumann R, Casaulta C, Simon D, Conus S, Yousefi S, Simon HU. Macrophage migration inhibitory factor delays apoptosis in neutrophils by inhibiting the mitochondriadependent death pathway. FASEB J 2003; 17: 22212230.

5 Bucala R. MIF rediscovered: cytokine, pituitary hormone, and glucocorticoid-induced regulator of the immune response. FASEB J 1996; 10: 1607-1613.

6 Donnelly SC, Haslett C, Reid PT, et al. Regulatory role for macrophage migration inhibitory factor in acute respiratory distress syndrome. Nat Med 1997; 3: 320-323.

7 Makita H, Nishimura M, Miyamoto K, et al. Effect of antimacrophage migration inhibitory factor antibody on lipopolysaccharide-induced pulmonary neutrophil accumulation. Am J Respir Crit Care Med 1998; 158: 573-579.

8 Tanino Y, Makita H, Miyamoto K, et al. Role of macrophage migration inhibitory factor in bleomycininduced lung injury and fibrosis in mice. Am J Physiol Lung Cell Mol Physiol 2002; 283: L156-L162.

9 Bacher M, Meinhardt A, Lan HY, et al. Migration inhibitory factor expression in experimentally induced endotoxemia. Am J Pathol 1997; 150: 235-246.

10 Calandra T, Bernhagen J, Metz CN, et al. MIF as a glucocorticoid-induced modulator of cytokine production. Nature 1995; 377: 68-71.

11 Bacher M, Metz CN, Calandra T, Mayer K, Chesney J, Lohoff $M$. An essential regulatory role for macrophage migration inhibitory factor in T-cell activation. Proc Natl Acad Sci USA 1996; 93: 7849-7854.

12 Rossi AG, Haslett C, Hirani N, et al. Human circulating eosinophils secrete macrophage migration inhibitory factor (MIF). Potential role in asthma. J Clin Invest 1998; 101 2869-2874.

13 Yamaguchi E, Nishihira J, Shimizu T, et al. Macrophage migration inhibitory factor (MIF) in bronchial asthma. Clin Exp Allergy 2000; 30: 1244-1249.

14 Korsgren M, Kallstrom L, Uller L, et al. Role of macrophage migration inhibitory factor (MIF) in allergic and endotoxininduced airway inflammation in mice. Mediators Inflamm 2000; 9: 15-23.

15 Elwood W, Barnes PJ, Chung KF. Airway hyperresponsiveness is associated with inflammatory cell infiltration in allergic Brown-Norway rats. Int Arch Allergy Immunol 1992; 99: 91-97.

16 Haczku A, Chung KF, Sun J, Barnes PJ, Kay AB, Moqbel R. Airway hyperresponsiveness, elevation of serum-specific $\operatorname{IgE}$, and activation of T cells following allergen exposure in sensitized Brown-Norway rats. Immunology 1995; 85: 598-603.

17 Waserman S, Olivenstein R, Renzi P, Xu LJ, Martin JG. The relationship between late asthmatic responses and antigenspecific immunoglobulin. J Allergy Clin Immunol 1992; 90: 661-669.

18 Nishihira J, Kuriyama T, Nishino H, Ishibashi T, Sakai M, Nishi S. Purification and characterization of human macrophage migration inhibitory factor: evidence for specific binding to glutathione and formation of subunit structure. Biochem Mol Biol Int 1993; 31: 841-850.

19 Mizue Y, Nishihira J, Miyazaki T, et al. Quantitation of macrophage migration inhibitory factor (MIF) using the one-step sandwich enzyme immunosorbent assay: 
elevated serum MIF concentrations in patients with autoimmune diseases and identification of MIF in erythrocytes. Int J Mol Med 2000; 5: 397-403.

20 Ohnuma N, Yamaguchi E, Oguri M, Kawakami Y. Hyposensitization attenuates airway inflammation and antigen-induced proliferative response by lymphocytes in a rat model of bronchial asthma. Respiration 1998; 65: 469-475.

21 Holgate ST, Robinson C, Church MK. Mediators of immediate hypersensitivity. In: Middleston E Jr, Reed CE, Regis EF, eds. Allergy Principles and Practice. 4th Edn. St Louis, Mosby, MO, 1993; pp. 267-301.

22 Lamkhioued B, Renzi PM, Abi-Younes S, et al. Increased expression of eotaxin in bronchoalveolar lavage and airways of asthmatics contributes to the chemotaxis of eosinophils to the site of inflammation. J Immunol 1997; 159: 4593-4601.

23 Ying S, Robinson DS, Meng Q, et al. Enhanced expression of eotaxin and CCR3 mRNA and protein in atopic asthma. Association with airway hyperresponsiveness and predominant colocalization of eotaxin mRNA to bronchial epithelial and endothelial cells. Eur J Immunol 1997; 27: 3507-3516.

24 Wills-Karp M, Luyimbazi J, Xu X, et al. Interleukin-13: central mediator of allergic asthma. Science 1998; 282: 2258-2261.
25 Grunig G, Warnock M, Wakil AE, et al. Requirement for IL13 independently of IL-4 in experimental asthma. Science 1998; 282: 2261-2263.

26 Walter DM, McIntire JJ, Berry G, et al. Critical role for IL-13 in the development of allergen-induced airway hyperreactivity. J Immunol 2001; 167: 4668-4675.

27 Baumann R, Casaulta C, Simon D, Conus S, Yousefi S, Simon HU. Macrophage migration inhibitory factor delays apoptosis in neutrophils by inhibiting the mitochondriadependent death pathway. FASEB J 2003; 17: 2221-2230.

28 Lamblin C, Gosset P, Tillie-Leblond I, et al. Bronchial neutrophilia in patients with noninfectious status asthmaticus. Am J Respir Crit Care Med 1998; 157: 394-402.

29 Fahy JV, Kim KW, Liu J, Boushey HA. Prominent neutrophilic inflammation in sputum from subjects with asthma exacerbation. J Allergy Clin Immunol 1995; 95: 843-852.

30 Louis R, Lau LC, Bron AO, Roldaan AC, Radermecker M, Djukanovic R. The relationship between airways inflammation and asthma severity. Am J Respir Crit Care Med 2000; 161: 9-16.

31 Global Initiative for Asthma (GINA). Global strategy for asthma management and prevention; NHLBI/WHO Workshop Report. Bethesda, National Institutes of Health, National Heart, Lung, and Blood Institute, 2002. Publication No. 02-3659. 